\title{
Truncamento e reduplicação no português brasileiro
}

\author{
Gabriel Araújo* \\ Vrije Universiteit Amsterdam
}

\section{Abstract}

This paper investigates the morphology of truncation and reduplication processes in Brazilian Portuguese (BP). Truncation (also known as abbreviation) is the word formation process in which a word is shortened without loss any meaning. I argue that the BP's truncated forms tend to be disyllabic and the secondary stress rhythm also plays a role in the process. The reduplication involves copy of a piece or a complete word, promoting a new lexical item. There are several kinds of reduplication (cf. COUTO, 1999), for the moment I will focus only on the total reduplication verb $_{\mathrm{i}}$-verb $\mathrm{b}_{\mathrm{i}}$. I will show that both processes are regular and predictable. Similarly, I will show the tendency of this word formation to have an open final syllable and binary feet, offering argument to the Emergence of the Unmarked Theory. 


\section{INTRODUÇÃO}

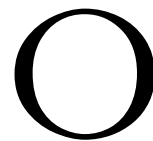

objetivo deste artigo é investigar os fenômenos de truncamento e reduplicação no Português Brasileiro (PB). Truncamento (também conhecido como abreviação ou encurtamento) é o processo pelo qual uma palavra é reduzida sem perda de valor semântico. Defenderei que a forma truncada tende a ser dissilábica e que o acento secundário representa papel crucial no processo. Já a formação de palavras por reduplicação ocorre quando uma parte (ou o todo) de uma seqüência fonológica é repetida resultando em uma nova informação morfológica. Apesar da variedade de formas que esse processo engloba (COUTO, 1999), centrar-me-ei apenas no processo de reduplicação total VERBO $_{\mathrm{x}}$-VERBO $\mathrm{x}$. Mostrarei que ambos os processos são regulares e previsíveis. No entanto, apesar de os dois processos resultarem em novos substantivos, as formas derivadas da reduplicação se comportam de maneira distinta em relação às regras morfofonológicas aplicáveis a essa classe em geral, enquanto os truncamentos são acessíveis à morfologia do nome. A contribuição do texto, portanto, é mostrar como funcionam os mecanismos ativos nesses processos. Ao mesmo tempo, pretendo assinalar a tendência, nesses processos, a favor de sílabas abertas e pés binários dissilábicos no $\mathrm{PB}$, fornecendo evidências para a teoria da Emergência do Não-marcado.

O texto está organizado da seguinte forma: em 1, defino as morfologias não-lineares e destaco as questões a serem tratadas. $\mathrm{Na}$ seção 2, trato do processo de truncamento e na 3 , analiso a reduplicação EERBO $_{\mathrm{x}}$-VERBO $\mathrm{x}$ em $\mathrm{PB}$. 


\section{MORFOLOGIAS NÃO-LINEARES EM PB}

Os principais processos morfológicos no Português são concatenativos, isto é, um elemento (prefixal, sufixal) é ligado linearmente a uma raiz a fim de se formar um novo item lexical. A formação por composição também é concatenativa. Nesse caso, um item lexical é ligado ao outro:

(1) (I) derivação prefixal (prefixo concatenado a uma morfema lexical) in + feliz: infeliz

(II) derivação sufixal (sufixo concatenado a um morfema lexical)

feliz + mente: felizmente

(III) composição (morfema lexical concatenado a outro) ponta + pé: pontapé

Outros processos morfológicos, apesar de marginais, são produtivos em Português, sobretudo no Português Brasileiro. ARAUJO (2001) denomina esses processos morfologias não-lineares (ou não-concatenativas), entendendo por não-linear a ausência de encadeamento. O encadeamento é substituído por supressão de elementos (truncamento), cópia total ou parcial da base (reduplicação), sobreposição ou amálgama (blending ou portmanteaux), acronímia (ou siglas), entre outros. Em (2), estão listados os processos nãoconcatenativos que comumente ocorrem no Português do Brasil (ARAUJO, 2001):

(2) (I) Truncamento ou Abreviação: mutilação de uma palavra existente, sem alteração de significado:

cerveja: cérva

refrigerante: refrí

(II) Reduplicação: um flexão da base verbal é copiada:

matar: mata-mata

pegar: pega-pega 
(III) Portmanteau ou Blending: sobreposição ou concatenação de dois elementos formando um novo: carnaval e natal: carnatal vampiro e capeta: vampeta

(iv) Acronímia: a partir de letras/sílabas iniciais das palavras de um nome, frase ou título, forma-se uma nova palavra Faculdade de Engenharia Civil: FEC ['f $\varepsilon$ kI] Banco Brasileiro de Descontos: Bradesco

Além dos processos listados em (2), tem-se aquele conhecido como derivação parassintética, na qual a aglutinação de prefixos e sufixos ao radical ocorre de forma simultânea, sem que exista vocábulo isolado formado apenas pelo primeiro ou pelo segundo. Dessa forma, palavras como entardecer não podem ser derivadas de *tardecer (mais prefixo en-) ou *entardar (mais sufixo-ecer). Os afixos, nessa formação de palavra, devem necessariamente ter acesso ao radical simultaneamente. Isso indica, portanto, um processo semelhante ao blending, pois a concatenação linear é incapaz de explicar a operação. De maneira semelhante, a reduplicação $\operatorname{VERBO}_{\mathrm{x}}-\mathrm{VERBO}_{\mathrm{x}}$ deve ser explicada levando-se em conta a cópia de uma base.

ARAUJO (2001) analisa a formação de palavras portmanteau. Dando seqüência àquela linha de trabalho, este artigo pretende analisar outros dois processos de formação de palavras no Português Brasileiro, o truncamento e a reduplicação. Os exemplos neste texto são do Português Brasileiro, sobretudo dos dialetos paulista e mineiro, exceto quando houver menção em contrário. ${ }^{1}$

\section{TRUNCAMENTO}

O processo de formação de palavras (PFP) por truncamento se caracteriza pela redução de uma palavra-matriz sem perda de valor semântico. ${ }^{2}$ A redução envolve perda de material segmental, em geral, silábico, que ocorre no limite direito da palavra. Para que o truncamento se aplique, a palavra-matriz deve possuir no mínimo três sílabas: 
(3) cerveja $\rightarrow$ cérva ${ }^{3}$

Vou comprar uma cerveja.

Vou comprar uma cérva.

refrigerante $\rightarrow$ refrí

O preço do refrigerante aumentou de novo.

O preço do refríaumentou de novo.

bijuteria $\rightarrow$ bijú

professor $\rightarrow$ prófi

A forma truncada e a palavra-matriz devem ser semântica e pragmaticamente intercambiáveis, ou seja, uma forma pode ser substituída pela outra sem que haja perda de sentido. Além disso, a palavra truncada geralmente possui duas sílabas, como em cerva, embora haja casos de truncamentos com três sílabas (respónsa). Essa definição permite identificar os dados em (4) como pseudotruncamentos (palavras que têm sido tratadas como truncamento, porém não apresentam as características dos truncamentos, segundo a definição acima).

(4) (a) metropolitano $\rightarrow$ ?metrô

Perdi o metrô por alguns instantes.

*Perdi o metropolitano por alguns instantes.

(b) deprê $\rightarrow$ depressão, ?deprimido, ?depressivo

A deprê do João contagiou os colegas na empresa.

A depressão do João contagiou os colegas na empresa.

*A deprimida do João contagiou os colegas na empresa.

Joana está muito deprê depois da eliminação da filha do torneio.

Joana está muito deprimida depois da eliminação da filha do torneio.

?Joana está muito depressiva depois da eliminação da filha do torneio.

*Joana está muito depressão depois da eliminação da filha do torneio. 
Os pseudotruncamentos podem entrar na língua via empréstimo direto, em geral, já truncadas nas línguas de origem, como é o caso de metrô (4a). No Português Europeu, no entanto, o dado em (4a) é gramatical, embora a forma truncada de metropolitano seja métro e não metrô, como no Brasil (essa questão será tratada adiante). Um segundo caso, mais extremo, ocorre quando o falante é incapaz de rastrear a palavra-matriz que gerou o pseudotruncamento, como em (4b). Nesse caso, a palavra deprê permite que mais de uma palavramatriz seja a base. Isso não se dá com os truncamentos verdadeiros, cujas palavras-matrizes são unívocas, rastreáveis e intercambiáveis. A palavra deprê (4b) é permutável com as palavras depressão e deprimida, ou seja, deprê não pode ser truncamento de depressão, pois também pode ser forma truncada de deprimida (4b), não sendo unívoca, rastreável e intercambiável e, portanto, um caso de pseudotruncamento. ${ }^{4}$

Há, ainda, os (pseudo) truncamentos derivados de afixos cultos de origem greco-latina, germânica, etc., ou de palavras com estrutura semelhante à composição por afixos, nas quais o elemento constitutivo, como por exemplo eletro (em eletrocardiograma) é identificado e usado metonimicamente. Nesses casos, a palavra-matriz será recuperável contextualmente.

(5) minissaia, minidicionário, etc

míni

microcomputador, microscópio, etc

mícro

fotografia, fotocélula, etc

fóto

gastrologia, gastrocentro, etc

gástro

eletrocardiograma, eletrodoméstico, etc

elétro

DUARTE (1999) não nomeia claramente as formações em (5) como palavras-prosódicas, preferindo utilizar o termo pseudoprefixos. Duarte se concentra na característica da truncabilidade dos pseudoprefixos bem como no fato de que, mesmo em compostos, essas palavras mantêm um acento (primário isoladamente e, em compostos, secundário). VIGÁRIO (2000, p. 587) aponta que no Português Europeu palavras formadas por composição morfológica, 
através da concatenação de radicais, apresentam dois comportamentos fonológicos distintos: podem não se distinguir fonologicamente de palavras simples (5a); ou podem apresentar propriedades fonológicas indiciadoras de que cada unidade contendo um radical corresponde a uma palavra prosódica (5b). As generalizações de Vigário se aplicam igualmente ao PB. As conclusões de Duarte e Vigário são basicamente as mesmas.

Os processos de truncamento têm sido tratados pela literatura como aleatórios e imprevisíveis. ${ }^{5}$ A falta de uma demarcação precisa entre o truncamento e os pseudotruncamentos têm garantido a manutenção da imprecisão nas descrições do fenômeno. Destacamse, entre os principais autores que abordam a questão, CUNHA (1990), SANDMANN (1991), ALVES (1990), MONTEIRO (1991), KEHDI (1992) e BASÍlIO (1987) no Brasil, e RIO-TORTO (1998) em Portugal. A abreviação vocabularé para CUNHA (1990, p. 130) resultante do "ritmo acelerado da vida intensa de nossos dias" que nos obriga a uma elocução mais rápida e econômica. A redução ocorre "até limites que não prejudiquem a compreensão”. Para ALVES (1990, p. 68) a "truncação constitui um tipo de abreviação em que uma parte da seqüência lexical, geralmente a final, é eliminada". Alves se utiliza de exemplos empregados pela imprensa escrita, como níver (de aniversário) e coq (de coquetel). Já para para SANDMANN (1991, p. 51-2) a abreviação é um tipo de formação de palavras bastante produtivo: "ela [a abreviação] é parte da vida moderna, com sua complexidade burocrática, administrativa, técnica e econômica, colaborando para a brevidade e densidade da comunicação lingüística. A maioria dos truncamentos é arbitrária”. Sandmann afirma, sem desenvolver a questão, que as "abreviações se caracterizam pelo aspecto de, às vezes, levar-se em conta uma suposta estrutura morfológica de palavra complexa". Sandmann se utiliza de truncamentos recolhidos da imprensa escrita como exemplos. MONTEIRO (1991, p. 174-5, 191) define a braquissemia como "o emprego de parte de um vocábulo pelo vocábulo inteiro”, cuja formação baseia-se no princípio da economia da linguagem. Monteiro dá ao truncamento 
o mesmo tratamento que autores citados acima. A acrossemia (combinação de sílabas ou fonemas extraídos dos elementos de um nome composto ou de uma expressão) "é proporcionalmente tão fértil quanto a braquissemia, já que na realidade ambos os processos têm a mesma natureza e funcionamento". Para KEHDI (1992, p. 28) o processo de "abreviação (...) não se pauta por critérios específicos e homogêneos". Ele destaca como exemplos as formas extra (de extraordinário) e foto (de fotografia). BASÍliO (1987, p. 37) considera que na "redução ou abreviação (...) temos uma palavra formada pela supressão de alguma parte da palavra derivante. (...) a parte a ser suprimida é, muitas vezes, imprevisível”. Para Basílio, uma variante da abreviação seria a redução que "encontramos em formas compostas". Basílio inclui em seu corpus exemplos como sampa (de São Paulo), granfa (de grã-fino), micro (de microcomputador). Contra essa literatura, mostrarei que o processo morfológico de truncamento é previsível e obedece a mecanismos possíveis de formação de palavras da língua, não sendo, por conseguinte, arbitrário ou resultado da rapidez da fala em contextos coloquiais. Além disso, o processo é amplamente atestado no Português Brasileiro, inclusive na fala de crianças (Rosa Attié Figueira, comunicação pessoal), como por exemplo palhaço $\rightarrow$ pálha, piscina $\rightarrow$ písça.

É possível afirmar que haja um padrão na formação do truncamento. A regularidade se mostra no fato de que há a redução de uma palavra-matriz (com, no mínimo, três sílabas) para uma palavra-truncada (geralmente com duas sílabas). Essa redução privilegia um dos limites da palavra-matriz. Entretanto, a posição do acento no truncamento é variada, pois há truncamentos cujo acento recai na penúltima ( $p i s c ̧ a)$ ou na última sílaba (bijú).
(6)
(I)
cerveja
$\rightarrow$ cérva $^{6}$
neurose $\rightarrow$ nêura
flagrante $\rightarrow$ flágra
(II) professor $\rightarrow$ prófi
bijuteria $\rightarrow$ bijú
refrigerante $\rightarrow$ refrí 
É necessário estabelecer, provisoriamente, dois tipos de truncamentos. No grupo (6I) estão as palavras truncadas a partir de palavrasmatrizes com três sílabas e acento na penúltima sílaba, o que implica que a palavra-matriz não possui acento secundário. No grupo (6II) estão as palavras com três ou mais sílabas e acento secundário.

Nas palavras trissilábicas com acento na penúltima, que não possuem acento secundário, invariavelmente formam-se truncamentos com duas sílabas e acento na penúltima sílaba. Em palavras trissilábicas (com dois acentos) e palavras com mais de três sílabas, a previsibilidade do acento torna-se mais complexa (adiante mostrarei que, embora complexa, não se trata de idiossincrática). Como a maioria das formas truncadas provêm de palavras com três ou mais sílabas, a relevância da posição do acento secundário tornase crucial. No entanto, a questão do acento secundário em PB é controversa. ABAURRE et al. (1997, p. 132) sugerem que "a questão da atribuição do acento secundário (...) é essencialmente rítmica". Basicamente, LEE (1995) assume que o acento secundário do PB ocorre em intervalos regulares a cada duas sílabas a partir do acento primário, sendo necessário postular adicionalmente uma regra de opcionalidade do pé degenerado e uma outra de desacentuação. Por outro lado, há também palavras (7) que possuem acento secundário não-iterativo, embora haja variação com formas cujo acento secundário é iterativo. A seguir, os acentos primários estarão marcados com um agudo (á) e os secundários com um grave (à):

(7) (i) cò pa ca bá na co pà ca bá na

(ii) pì ra ci cá ba pi rà ci cá ba

Pode-se argumentar, tentativamente, que essas palavras são segmentadas pelo falante nativo como um composto, por exemplo, copa+cabana, e, portanto, a aplicação do acento considera duas palavras prosódicas ao invés de uma. Sendo assim, os acentos primários de cada componente são mantidos (conforme as previsões de COLLISCHONN, 1996, p. 50). 
Entretanto, acredito que além da função rítmica, a gramática da língua faz uso do acento secundário, quando disponível, na formação de truncamentos. A hipótese é testada com pares mínimos truncados cuja distinção é fundamentada unicamente na posição do acento secundário, em (8). A variação dialetal implica na diferença das formas truncadas. Os exemplos em (i) são da variante paulista, enquanto (ii) exemplificam a variante paraense.

\begin{tabular}{|c|c|c|c|}
\hline exposição & $\begin{array}{l}\text { (i) } \\
\text { (ii) }\end{array}$ & $\begin{array}{l}\text { èx po si ção } \\
\text { ex pò si ção }\end{array}$ & $\begin{array}{l}\text { éxpo } \\
\text { expô }\end{array}$ \\
\hline Kilimanjaro ${ }^{7}$ & $\begin{array}{l}\text { (i) } \\
\text { (ii) }\end{array}$ & $\begin{array}{l}\text { kì li man já ro } \\
\text { ki lì man já ro }\end{array}$ & $\begin{array}{l}\text { kíli } \\
\text { kilí }\end{array}$ \\
\hline refrigerante & $\begin{array}{l}\text { (i) } \\
\text { (ii) }\end{array}$ & $\begin{array}{l}\text { re frì ge rán te } \\
\text { rè fri ge rán te }\end{array}$ & $\begin{array}{l}\text { refrí } \\
\text { réfri }\end{array}$ \\
\hline
\end{tabular}

A posição do acento secundário também é responsável pela diferença crucial entre as formas prófi e profí, derivadas respectivamente de professor e profissional (dialetos paulista e gaúcho). ${ }^{8}$
(9) prò fe ssór
prófi
pro fì ssi o nál
profí

Entretanto, a alocação da posição do acento secundário não é o único fator na formação de truncamento. Uma série de condições devem se aplicar:

(10) (i) a palavra-matriz deve ter três ou mais sílabas;

(ii) contando-se da esquerda para a direita, selecionam-se as duas primeiras sílabas da palavra e eliminam-se as restantes: $\sigma_{1} \sigma_{2} \sigma_{3} \sigma_{4} \sigma_{5} \sigma_{6} \ldots \rightarrow \sigma_{1} \sigma_{2}$;

(iii) as condições fonotáticas da língua devem ser respeitadas;

(iv) o acento deve ser atribuído à sílaba que guardava acento secundário na palavra-matriz. Se não houver acento secundário, acentua-se a penúltima sílaba. 
Em (11) e (12), as condições apresentadas em (10) são testadas. Em (11), a condição (iii) não se aplica, enquanto em (12), a condição (iv) é crucial para diferenciar o par professor/profissional.

(11) truncamento: refrigerante $\rightarrow$ ?

condição (i): $\quad$ satisfeita, ou seja, a palavra possui mais de três sílabas

condição (ii): resulta em $\rightarrow{ }_{\sigma \mathbf{1}}(\text { re })_{\sigma \mathbf{2}}($ fri)

condição (iii): não se aplica

condição (iv): acento secundário: re ${ }^{2}$ fri ge ran te $\rightarrow$ fri

resultado: $\quad$ refrigerante $\rightarrow$ refrí [he'fri]

Os truncamentos gerados pelas bases professor e profissional destacam a importância do papel do acento secundário:

(12) truncamento:

professor $\rightarrow$ ?

profissional $\rightarrow$ ?

condições (i-iii): $\quad$ satisfeitas de maneira idêntica

condição iv:

acento secundário: ${ }^{2}$ professor $\rightarrow$ pro

pro²fissional $\rightarrow f i$

resultado:

professor $\rightarrow$ prófi ${ }^{9} \quad c f$.['pro.fi]

profissional $\rightarrow$ profi cf. [pro.'fi]

Desconsiderar o papel do acento secundário na formação de truncamentos criará um problema: como explicar a existência de pares mínimos e a posição do acento primário nas palavras truncadas em geral, tendo em vista as possibilidade dentro do mesmo dialeto?

Uma segunda classe de truncamentos engloba as formas truncadas trissilábicas. Embora menos comuns do que os truncamentos dissilábicos, os trissilábicos regularmente possuem acento na penúltima sílaba e a tendência para preservar a raiz da palavra-matriz. 


\begin{tabular}{|c|c|c|}
\hline $\begin{array}{l}\text { palavra-matriz } \\
\text { delegado }\end{array}$ & $\begin{array}{l}\text { truncamento } \\
\text { deléga }\end{array}$ & $\begin{array}{l}\text { sufixo eliminado } \\
\text {-ado }\end{array}$ \\
\hline traficante & trafica & -ante \\
\hline português & portúga & -ês \\
\hline salafrário & saláfra & -rio \\
\hline responsabilidade & respónsa & -bilidade \\
\hline
\end{tabular}

A necessidade de manter a especificação lexical força o truncamento, permitindo a violação da condição (10ii), segundo a qual o truncamento deve manter apenas as duas sílabas à esquerda da palavra-base. Diante dos dados em (13), deve-se incluir uma condição no esquema em (10) que garanta fidelidade ao conteúdo lexical da palavra-matriz, nas situações em que a condição (10ii) falhe em aplicar. Ou seja, se a lexicalidade mesma da palavra é expressa por sua raiz, manter o máximo possível desse elemento idiossincrático é preferível, senão fundamental. Caso contrário a possibilidade de rastreamento lexical estaria comprometida. A manutenção da base fica evidenciada pela terminação uniforme desse tipo de truncamento, ou seja, a vogal final é sempre /a/. Nesse caso, a epêntese é a alternativa ao apagamento que poderia provocar a perda da lexicalidade e, ao mesmo tempo, impedir codas proibidas como *salá $f r$, truncamento agramatical de salafrário.

Adicionalmente, os truncamentos com sílabas finais terminadas em codas possíveis (R, S, L, N) sofrem apagamento da coda final, ${ }^{10}$ como em retardado $\rightarrow$ rêta, ou pervertida $\rightarrow$ pérva.$^{11}$

A análise mostra que a tendência geral do truncamento é formar uma palavra dissilábica com a sílaba final aberta, bem como a manutenção de estruturas prosódicas alinhadas à direita na palavra-base. O termo tendência é utilizado nesse texto dentro do arcabouço da teoria da Otimalidade (PRINCE \& SMOLENSKY, 1993). Na Teoria da Otimalidade, as tendências são formalizadas como restrições, resultando na necessidade da distinção entre tendência e restrição verdadeira. A primeira ocorre quando a restrição é ordenada abaixo de outra. A última ocorre quando a restrição é dominante (em relação a todas as outras restrições). Localmente, a tendência mostra a 
propensão de um dado ordenamento (mesmo que seja desconhecido) a selecionar determinado padrão. Isso é numericamente relevante, uma vez que "a maioria" dos dados se comporta mediante essa propensão. Dessa forma, dados discordantes estão além do escopo da tendência e, certamente, sob a influência de uma restrição verdadeira.

Porém, outros fatores, sobretudo a fidelidade à base, conspira contra essa tendência. Portanto, uma estrutura mais marcada se debate com a necessidade de fidelidade ao input. Essas circunstâncias fornecem argumentos para o ordenamento de restrições como defende a Teoria da Otimalidade clássica (PRINCE \& SMOLENSKY, 1993, McCARTHY \& PRINCE, 1993, 1995, entre outros). A diferença dialetal manifestar-se-á na variedade do ordenamento das restrições. Dessa forma, a explicação para a variedade de truncamentos em palavras como exposição estaria diretamente relacionada à restrição prosódica do acento secundário, a depender da permissividade do dialeto. ${ }^{12}$ Concomitantemente, explicar-se-ia a possibilidade do truncamento a partir da base metropolitano no PE (métro, na qual a sílaba contendo acento secundário, me, ganha proeminência). Nessa palavra, a primeira sílaba é proeminente no PE, enquanto no PB tanto a sílaba me, como a sílaba tro podem carregar o acento secundário. Entretanto, metrô deve ser eliminado como truncamento no PB por não ser intercambiável com a palavra metropolitano, pelo menos não na acepção de transporte público. É possivel que metro seja truncamento da palavra metropolitana e em seguida interpretada como radical, como por exemplo na composição METROBEL (sigla da extinta Companhia de Transportes Públicos da Região Metropolitana de Belo Horizonte). Dessa forma, a análise aqui apresentada não propõe que a palavra metrô seja derivada no PB de metropolitano como é no PE. Acredito que metrô, como já foi afirmado, entra emprestada diretamente de sua forma francesa metrô.

Ao mesmo tempo, a análise apresentada aqui pretende contribuir de uma maneira geral para nosso entendimento das diferenças rítmicas entre o PE e o PB, mostrando que o fato de as variantes possuírem sistemas de acento secundário diferentes (ABAURRE, SANDALO \& GALVES, 1999) é relevante para a gramática como um todo. 


\section{REDUPLICAÇÃO}

Os processos de reduplicação podem ser parciais (quando parte da palavra é reduplicada) ou totais (quando toda a palavra é reduplicada). A reduplicação é um processo morfológico considerando que se trata de um tipo de afixação, pois a parte reduplicante deve ser linearmente ligada preposta (i.é, um prefixo) ou posposta (i.é, um sufixo) à palavra-matriz. Para MARANTZ (1982, p. 456), a reduplicação total ocorre quando o morfema reduplicativo toma todos os elementos emprestados à raiz, incluindo a estrutura silábica e melódica. A afixação normal, por sua vez, por já possuir o esqueleto CV e a melodia fonêmica, nada toma emprestado à raiz. Isso esclarece a razão pela qual o reduplicante deve ser estruturalmente vazio. Além disso, a reduplicação funciona como um conteúdo morfológico. Nas línguas indonésio (MARANTZ, 1982; NASH, 1980) e diyari (MCCARTHY \& PRINCE, 1994, AUSTIN, 1981), por exemplo, a reduplicação marca o morfema de plural. Na primeira língua a reduplicação é total, enquanto na segunda, ela é parcial (copia o pé inicial, menos a coda da segunda sílaba):

(14) Reduplicação em indonésio

$\begin{array}{llll}\text { kurdu } & \text { 'criança' } & \text { kurdukurdu } & \text { 'crianças' } \\ \text { kamina } & \text { 'menina' } & \text { kaminakamina } & \text { 'meninas' }\end{array}$

Reduplicação em diyari

wi.1a 'mulher' wi.1a-wi.1a 'mulheres'

Do ponto de vista fonológico, o reduplicante não possui especificação segmental, pois sua especificação é copiada da palavrabase (WILBUR, 1974). O reduplicante não pode possuir especificação segmental porque, em cada palavra reduplicada, o elemento reduplicado deve ser necessariamente copiado da base, parcial ou totalmente. Se o elemento reduplicante fosse especificado, todas as palavras reduplicadas deveriam conter um elemento fixo imutável. Portanto, a reduplicação envolve identidade fonológica entre a base a forma reduplicada. 
A reduplicação em $\mathrm{PB}$ atua como um morfema aspectual de iteratividade, isto é, a palavra reduplicada funciona como uma forma repetitiva da base. Iteração (repetição) deve ser distinguida de duração. Na língua mwera (HARRIES, 1950; BYBEE et al. 1994, apud KAGER, 1999), radicais monossilábicos são triplicados e radicais polissilábicos são duplicados, a fim de indicar iteratividade.

(15) Reduplicação em Mwera

lya 'comer' lyalyalya

gwa 'cair' gwagwagwa 'cair e cair de novo'

pinga 'querer' pinga-pinga 'procurar'

jenda 'viajar' jenda-jenda 'sair em busca de aventuras'

A iteração sinaliza, portanto, que uma ação é continuamente repetitiva. Esse é um tipo comum de reduplicação nas línguas do mundo. Os dois primeiros exemplos são interpretados como um único evento, enquanto os dois últimos são menos claros sem o contexto geral, embora também se refiram à repetição.

Antes de discutir o tema central desta seção, pretendo estabelecer critérios para a reduplicação em PB e ao mesmo tempo descartar aqueles que não se encaixam na definição que adoto. ${ }^{13} \mathrm{Em}$ primeiro lugar, todas as palavras-base são formas derivadas de verbos (note que a reduplicação em mwera também é derivada de verbos). Além disso, as bases devem possuir conteúdo lexical independente, ou seja, formas como reco-reco são desconsideradas pelo fato de que reco não existe isoladamente, pelo menos com a acepção que tem na palavra reduplicada. ${ }^{14}$ Se, isoladamente, palavras como reco, trim, etc. não existem, ${ }^{15}$ é desnecessário acreditar que se trata de um processo reduplicativo, porque elas só ocorrem na forma reduplicada. Ao mesmo tempo, formas reduplicadas com verbos semânticos opostos (vai-volta, leva-e-traz, etc.) não são consideradas exemplos de reduplicação, pois nenhum elemento estrutural foi efetivamente dobrado. Da mesma forma, expressões idiomáticas como és-não-és, vai-não-vai ou sai-não-sai também estão excluídas. A exclusão se deve ao fato de que ambas as pseudo-reduplicações não se estruturam 
no modelo geral de reduplicação $[123]_{\mathrm{x}} \rightarrow[123123]_{\mathrm{y}}$. A palavra reduplicada deve, também, formar um novo item lexical.

COUTO (1999) contém uma lista variada de processos ou pseudo-processos de reduplicação no Português do Brasil, incluindo recursos estilísticos como reduplicação poética. Embora Couto considere um sem-fim de processos, limitar-me-ei somente aos processos sincrônicos VERBO - -VERBO $\cdot{ }^{16}$

Meu objetivo, portanto, é tratar a reduplicação como processo morfológico comum. Isso supõe que a reduplicação deve ser vista como um mecanismo de formação de palavras produtivo e morfologicamente funcional.

Os exemplos em (16) são de reduplicação no PB. ${ }^{17} \mathrm{O}$ asterisco seguindo a palavra indica que o termo está dicionarizado (FERREIRA, 2000). Os significados desses termos, uma vez que todos são itens lexicais diferentes de suas bases, também estão no dicionário. Na entrada do dicionário, os exemplos são acusados como brasileirismos. Essa observação é pertinente, porque esse fenômeno lingüístico é exclusivo do PB, sendo completamente ausente no Português Europeu.
(16) corre-corre*
pega-pega*
mata-mata*
pula-pula*
pisca-pisca
gira-gira*
rola-rola*
quebra-quebra*

As semelhanças estruturais dos dados em (16) são notáveis. Como foi notado anteriormente, todos os exemplos são de reduplicação total. Não ocorre nenhuma modificação estrutural (queda de consoante, metátese, etc) na palavra reduplicada em relação à base. A forma de base é a terceira pessoa do singular de um radical verbal dissilábico. O fato de a base ser a terceira pessoa do singular do modo indicativo pode estar associado às características menos marcadas (como será mostrado adiante) dessas formas.

A primeira questão deve tratar do fato de a reduplicação ser total. Como as opções fonotáticas da língua governam, de uma maneira geral, o leque de opções na reduplicação, os elementos reduplicados 
formam, estruturalmente, um subconjunto das opções fonotáticas da língua. A preferência por um subconjunto contendo sílabas abertas (com acento na penúltima) dá suporte às hipóteses que defendem que a estrutura silábica menos marcada, em PB, é consoante-vogal (cf. a análise de Collischon sobre apêntese - COLLISCHON, 1996).

Outra tendência é a base reduplicada possuir um pé dissilábico com acento na penúltima sílaba. Vários autores (BISOL, 1992; LEE, 1995; COLISCHONN, 1996; WETZELS, 1995, etc.) mencionam que o pé dissilábico é canônico em português. Essa suposição está, por exemplo, presente em quase todas as análises do acento primário em PB (LEE, 1995; WETZELS, 1995, etc). Como já foi mostrado, o processo de truncamento também segue essa tendência (cf. seção 2 acima e ARAUJO, 1999).

Estrutura silábica menos marcada é uma tendência na reduplicação. Além disso, o processo ocorre somente com formas verbais dissilábicas, cuja terceira pessoa do singular termine em vogal. A presença de um elemento na coda, no caso, uma nasalização, impede o engatilhamento da reduplicação. Dessa forma, verbo como reter, cuja forma de terceira pessoa do singular é retém, não se reduplica. ${ }^{18}$ A maioria absoluta (cerca de 90\%) dos dados é composta por radicais dissilábicos. Embora originárias de verbos dissilábicos, cai-cai (ca.ir), rói-rói (ro.er) e põe-põe (verbo monossilábico) fogem à generalização ${ }^{19},{ }^{20}$.

A mudança de classe (de verbo para substantivo) é propriedade morfológica da reduplicação em PB (bem como do truncamento). Isso implica que, por ser um substantivo, a forma gerada deve ser suscetível às regras que comumente se aplicam à classe de substantivos. Os exemplos em (17) mostram ocorrências possíveis (gramaticais) em que palavras geradas a partir de truncamentos se mostram transparentes às regras gerais da morfologia do $\mathrm{PB}$, no caso, aplicação de diminutivo e pluralização. ${ }^{21}$

(17) Vamos começar bebendo um refrizinho bem gelado.

Duas cervas podem refrescar a discussão. 
Embora o Dicionário Aurélio registre as formas do plural para as palavras reduplicadas (18), meu julgamento de falante nativo não as aceita como completamente gramaticais.

(18) O campeonato chegou na fase do mata-mata.

?O campeonato chegou na fase dos mata-matas.

MARANTZ (1982), tratando de problema de natureza semelhante, a saber, a sub- e a superaplicação de regras fonológicas a palavras reduplicadas, defende que, considerando os componentes lexicais e fonológicos da gramática da língua como distintos (e é isso que a Fonologia Gerativa faz), nota-se que não existe problema de aplicação de regras uma vez que o ordenamento de regras pode tornar as palavras reduplicadas opacas ou transparentes às regras, a depender do ciclo em que elas são geradas. Isso implica que, para a Morfologia do PB, na visão da Fonologia Lexical, as regras de reduplicação são tardias, aplicando-se após regras morfofonêmicas. ${ }^{22}$ Para a Teoria da Otimalidade, a solução também implica postular que uma Restrição Bloqueadora domine Restrições Engatilhadoras e de Fidelidade, ou seja, a reduplicação dominaria as restrições prosódicas e morfológicas, normalmente ativas na língua. Dessa forma, o processo de reduplicação seria alimentado por uma fonte do output e, portanto, teria um comportamento diferenciado das formas derivadas diretamente de inputs (para uma discussão detalhada, ver McCARTHY \& PRINCE, 1995). No entanto, basicamente, os modelos derivacionais e paralelos enfrentam o mesmo problema. O que o primeiro chama de regra póslexical, o último chamará de relação de correspondência output-output.

As diferenças na gênese lexical entre as variantes brasileira e européia do português permanecem como uma questão em aberto. Nesse sentido, trabalhos comparando as duas variantes são fundamentais. RIO-TORTO (1998) tem tratado dos processos morfológicos no Português Europeu, com descrições detalhadas da maioria dos processos (ou talvez todos), mencionando também processos minoritários. 
As descrições de Rio-Torto chamam atenção para o fato de que uma série de processos de formação de palavras, praticamente ausentes no PE, são comuns no PB, como por exemplo a reduplicação, o truncamento, a formação portmanteau (blending, que ela denomina "cruzamento ou intersecção supressiva de segmentos mediais") cuja "disponibilidade e produtividade (...) não tem paralelo no português europeu" (RIO-TORTO, 1998, p. 21), entre outros.

Sobre a reduplicação, Rio-Torto não menciona explicitamente a situação no Português Brasileiro, porém mostra (1998, p. 17) que no Português Europeu "[a reduplicação] manifesta-se fundamentalmente em registos expressivos, na linguagem infantil (dóidói, pópó, papá, pépé, tau-tau), na linguagem familiar (titi, vóvó), e em vocábulos onomatopáicos (miau-miau, piu-piu). Alguns produtos formados por este processo encontram-se já lexicalizados (bombom), ou em vias disso".

Os processos de truncamento, por sua vez, são rapidamente examinados por Rio-Torto, embora a autora não se aprofunde na questão. As observações de Rio-Torto são, em geral, as mesmas de SANDMANN (1991), ALVES (1990) e BASÍLIO (1991): há redução da extensão da palavra, não há alteração semântica. A base da análise de Rio-Torto é a confirmação de que "no português europeu os processos mais produtivos de formação de palavras são a afixação - por sufixação, por prefixação e por circunfixação - e a composição" (RIO-TORTO, 1998, p. 23). Isso também se aplica ao Português Brasileiro, uma vez que os processos de composição e afixação são os mais comuns.

\section{CONCLUSÃO}

A questão a ser respondida é por que o PB faz uso de um elenco de outros processos, enquanto o PE não o faz? Comparandose o Português Europeu ao Brasileiro, pode-se inferir que a variedade européia faz uso de um subconjunto das possibilidades de formação de palavras da variante ultramarina. Isso quer dizer que ambas dispõem de um conjunto nuclear de regras de formação de palavras, 
enquanto o PB lança mão de recursos ausentes na Gramática do PE. Pode-se especular que a variante européia mantém-se conservadora, enquanto a variante brasileira sofreu influência dos vários substratos indígenas ou africanos durante sua formação.

COUTO (2000) descreve os processos de reduplicação nos Crioulos de Base Portuguesa (CBP) e também inclui o Português Brasileiro "uma vez que o português brasileiro tem sempre sido mencionado no contexto da crioulização do português no ultramar" (COUTO, 2000, p. 13). Couto nota que a reduplicação, via de regra, é um processo produtivo e amplamente atestado nos crioulos de base portuguesa. No entanto, não atribui a gênese da reduplicação nos CBP apenas aos seus substratos (COUTO, 2000, p. 15), mas defende que a reduplicação e os processos composicionais, como um todo, são os primeiros a surgir, por serem menos marcados. Se, por um lado, a reduplicação no $\mathrm{PB}$ pode, especulativamente, estar associada à sua gênese, por outro lado, sabe-se pouco sobre a morfologia das línguas que o influenciaram. Essas influências, por hipótese, teriam alterado o padrão das regras morfofonológicas do PE na Colônia. No entanto, seria necessário um estudo dos substratos para testar essa hipótese.

Como foi mostrado, tanto o processo de truncamento como o de reduplicação tendem a preferir formas dissilábicas com sílabas finais abertas. Nos truncamentos, em geral, codas em sílabas são evitadas com duas estratégias. A primeira é a síncope da coda / R/ final (e, por hipótese, as outras codas finais possíveis ${ }^{23}$, como em pérva. No entanto, quando a síncope provoca perda de recuperabilidade do próprio item lexical, ocorre manutenção da coda através da ressilabificação e epêntese, a segunda estratégia, como em sa.lá.fra. Em ambos os casos, há o banimento de sílaba final com coda. Na reduplicação, verbos como abster, manter, etc. não são reduplicados, pois conteriam duas codas finais (como em *abstém-abstém). Nesse cenário, a idéia de McCARTHY \& PRINCE (1994) sobre a emergência do não-marcado representa papel fundamental.

A idéia da emergência do não-marcado baseia-se na tendência para a superficialização das estruturas menos marcadas da língua, 
no caso do Português Brasileiro, sílabas finais abertas e pés binários, em determinados contextos. Entretanto, trata-se de uma tendência. Outras restrições podem dominar as não-marcadas, forçando a ocorrência de estruturas marcadas. O Português, por exemplo, não bane sílabas finais com codas (embora os elementos que possam ocorrer nessa posição sejam limitados). Contudo, vários processos, incluindo o truncamento e a reduplicação, eliminam codas finais. $\mathrm{Na}$ reduplicação e no truncamento, pés binários silábicos são preferidos, embora alguns fatores forçem o aparecimento de estruturas com uma (rói-rói) ou três sílabas (agarra-agarra). Novamente, conclui-se que o aparecimento de estruturas marcadas é forçado por outras restrições. McCARTHY \& PRINCE (1994, p. 28) argumentam que:

"[w]ithin Optimality Theory, even dominated constraints may be visibly active, under appropriate circumstances. This property, which we have dubbed emergence of the unmarked, is fundamental to от, since it follows from the essential notions of constraint ranking and violation under domination (PRINCE e SMOLESNKY 1993). It sharply differentiates it from approaches to linguistic structure and interlinguistic variation based on parameters, rules, or other devices that see linguistic principles in globally all-or-nothing terms."

Esse texto pretendeu definir os processos de truncamento e de reduplicação no Português Brasileiro. A falta de uma circunscrição precisa desses fenômenos tem sido responsável pelos equívocos no seu tratamento. Em seguida, destaquei as tendências dos dois processos mostrando seus pontos de intersecção. O valor da análise apresentada reside no fato de destacar que as semelhanças entre os dois processos decorrem da tendência de o Português Brasileiro preferir estruturas menos-marcadas. Devido aos múltiplos aspectos da variação dialetal, mais trabalhos nessa área iluminariam algumas das questões aqui levantadas. 


\section{NOTAS}

* Um trecho deste artigo foi apresentado no Colóquio Acento no Português, realizado no dia 22 de outubro de 1999 no Instituto de Estudos da Linguagem da Unicamp. Gostaria de agradecer a Seung Hwa-Lee, Leonardo Couto, Rosa Attié Figueira, Filomena Sândalo e aos participantes do Colóquio por valiosos comentários e sugestões. Agradeço também a Leo Wetzels, Demerval da Hora, três pareceristas desta Revista de Estudos da Linguagem e especialmente Seung Hwa-Lee pela revisão e comentários finais. Essas pessoas, no entanto, não devem ser penalizadas pelos erros remanescentes.

${ }^{1}$ Como será mostrado adiante, a diferença dialetal representa um papel relevante na formação de truncamento.

${ }^{2}$ Restringir-me-ei à formação estrutural das morfologias não-concatenativas, deixando de lado o aspecto semântico.

${ }^{3}$ Sempre que possível evitarei transcrições fonéticas. Quando necessário, marcarei a posição do acento com um agudo e o acento secundário com um grave.

${ }^{4}$ Um parecerista argumenta que a agramaticalidade do terceiro exemplo de $4 \mathrm{~b}$ é previsível e que, além disso, pode-se defender que no caso da palavra deprê há duas palavras-fonte possíveis (fato que, por definição, a eliminaria).

${ }^{5}$ Incluindo os truncamentos e os pseudotruncamentos.

${ }^{6}$ Não tratarei das alterações entre as vogais médias porque são irrelevantes aqui. WETZELS $(1992,1995)$ discute essas alternâncias.

${ }^{7}$ Kilimanjaro é um restaurante na cidade de Campinas, cujo nome foi baseado na montanha africana. Os diferentes truncamentos (kíli e kilí) espelham variedades dialetais de dois informantes.

${ }^{8}$ Note que a palavra profissional também poderia ter acento secundário na sílaba PRO (cf. COLLISCHON, 1996). No entanto, nos dialetos dos informantes, o acento secundário ocorre na sillaba FI. De qualquer forma, a variação será explicada adiante.

${ }^{9}$ No final de palavra, no PB, vogais médias [e, o] átonas finais são alçadas para $[i, u]$ respectivamente.

${ }^{10}$ Não discutirei a posição de coda no PB. Utilizo as representações dos elementos possíveis com capitais maiúsculas, à maneira de Mattoso Câmara.

${ }^{11}$ De forma não-prevista, o truncamento da palavra aniversário é níver (ALVES, 1990) . É difícil provar que se trata de uma formação de truncamento influenciada pela ortografia e, portanto, fugiria às regras das formações orais. No entanto, é um caso em que a coda final não é eliminada. Além disso, não possuo exemplos com outras codas finais possíveis $(\mathrm{S}, \mathrm{L}, \mathrm{N})$ em que não ocorra o apagamento final. Deixarei exceções como essa para um desenvolvimento futuro. 
${ }^{12}$ Seung Hwa-Lee (comunicação pessoal) acredita que haja variação de acento secundário em todos dialetos do $\mathrm{PB}$, não sendo portanto variável em cada dialeto. Para ele, o que pode prevalecer é a regra prioritária, a depender do dialeto: pé degenerado ('felicidade) ou acento secundáro normal (fe'licidade). Dessa forma, a variação dialetal tornar-se-ia relevante.

${ }^{13}$ Parte deste trabalho foi escrito na mesma época em que Hildo Honório do Couto (COUTO, 1999) publicou seu artigo “A Reduplicação em Português”, embora nossas abordagens sejam distintas. Encorajo o leitor a ler o texto de Couto. Lá encontra-se uma coleção de processos de reduplicação.

${ }^{14}$ No Brasil, em alguns registros, reco pode ser usado como gíria para soldado.

${ }^{15}$ A partir desses critérios, formas onomatopaicas como tico-tico, oba-oba, tecoteco são descartadas como reduplicações.

16 Reduplicação com dois verbos distintos, como por exemplo vai-vém, será desconsiderada aqui.

${ }^{17}$ No ANEXO forneço uma lista extensa de exemplos de reduplicação e truncamento.

${ }^{18}$ De um corpus de 30 mil palavras, cerca de 750 são verbos dissilábicos, dos quais sete possuem elemento em coda na terceira pessoa do singular (cf. ele/ela abstêm, detêm, contêm, mantêm, obtêm, retém, sustêm) e são irreduplicáveis. A princípio, potencialmente, os verbos dissilábicos restantes são reduplicáveis.

${ }^{19}$ As bases dos exemplos cai-cai e rói-rói não podem ser dissilábicas. A vogal ortográfica $i$ representa, nesses exemplos, parte de um ditongo. Há, na língua, bases dissilábicas como [ka.'i] e [ro.'i] que não se reduplicam. Essas bases dissilábicas, por não serem formas da terceira pessoa do singular do modo indicativo, ficam fora do escopo da reduplicação.

${ }^{20}$ Da mesma forma, agarra-agarra, empurra-empurra e esconde-esconde são exemplos de reduplicações com bases trissilábicas. Dois pareceristas apontam para o fato de que as primeiras sílabas (nas reduplicações trissilábicas) podem ser vistas e analisadas como prefixo pelos falantes. Outros processos morfofonológicos ativos em formações como tropelar de atropelar e bacate de abacate, entre outros, podem fornecer uma direção para o entendimento do comportamento dessas sílabas iniciais sem onset. Deixarei essa questão em aberto.

${ }^{21}$ O Dicionário Aurélio registra a possibilidade de pluralização em nomes reduplicados, como por exemplo pega-pega: pega-pegas ou pegas-pegas. No entanto, todos os informantes consultados, inclusive eu, estranham essas pluralizações.

${ }^{22}$ Seung Hwa-Lee argumenta que se se levar em conta que a forma do verbo na reduplicação é o radical (portanto não a forma flexionada, $3^{\text {a }}$ pessoa singular), a fonologia lexical explica a reduplicação como simples composição, sendo portanto regra lexical. 
${ }^{23} \mathrm{Na}$ nativização de empréstimos, codas finais /S/ são opcionalmente ressilabificadas, como em miss mi.sse, stress es.tre.sse. Note que a ressilabificação é opcional, uma vez que a pronúnica ['mis] e [is.'tres] são atestadas também. De qualquer forma, a existência das variantes ressilabificadas indica a tendência em direção à proibição de codas finais.

\section{REFERÊNCIAS BIBLIOGRÁFICAS}

ABAURRE, Bernadete et al. Reflexões sobre a interface sintaxe-fonologia. Anais do Seminário GEL. Campinas: IEL, 1997, p. 127-134.

ABAURRE, Bernadete; SANDALO, Filomena; GALVES, Charlotte. Otimizando o ritmo em português. IEL-Unicamp, 1999. (Inédito).

ALVES, Ieda. Neologismo: criação lexical. São Paulo: Ática, 1990.

ARAÚJO, Gabriel. Truncamento no português do Brasil. Colóquio Acento no Português. IEL-Unicamp, 1999.

ARAÚJO, Gabriel. Morfologia não-concatenativa em português: os portmanteaux. Cadernos de Estudos Lingüisticos, 39, 2001. No prelo.

AUSTIN, Peter. A grammar of diyari, South Australia. Cambridge: CUP, 1981.

BASílIO, M. Teoria lexical. São Paulo: Ática, 1987.

BISOL, Leda. O acento: duas alternativas de análise. UFRGS/PUCRS, 1992. (Inédito) BISOL, Leda. O acento e o pé métrico binário. Letras de Hoje, 98, p. 25-36, 1994.

CAGLIARI, Luiz; MASSINI-CAGLIARI, Gladis. Quantidade e duração silábicas em português do Brasil. DELTA, 14 (n⿳o especial), p. 47-59, 1998.

CÂMARA Jr., Joaquim Mattoso. Estrutura da lingua portuguesa. Petrópolis: Vozes, 1970.

COLINA, Sônia. Spanish truncation process: the emergence of the unmarked. Linguistics, 34, p. 1199-1218, 1996.

COLLISCHON, Gisela. Acento secundário em português. Letras de Hoje, 29 (4), p. 43-53, 1996.

COLLISCHON, Gisela. Acento e epêntese numa abordagem pela от. UFRGS, 1999. (Inédito).

COUTO, Hildo Honório do. A reduplicação em português. Lusorama, 40, p. 29-40, 1999.

COUTO, Hildo Honório do. A reduplicação nos crioulos portugueses. In: D'ANDRADE, Ernesto; MOTA, Maria A.; PEREIRA, Dulce (Org.). Crioulos de base lexical portuguesa. Lisboa: Associação Portuguesa de Lingüística, p. 61-80, 2000. 
CUNHA, Celso. Gramática da lingua portuguesa. 12. ed. Rio de Janeiro: FAE/ MEC, 1990.

DUARTE, Paulo M. T. A identificação do prefixo nas diversas abordagens lingüísticas. DELTA, v. 14, n. 1, p. 141-168, 1998.

DUARTE, Paulo M. T. Contribuição para o estudo do pseudoprefixo em português. DELTA, v.5, n.2, 1999.

FERREIRA, Aurélio. Dicionário Aurélio 2000. Rio de Janeiro: Nova Fronteira, 2000.

KAGER, Rene. Optimality Theory. Cambridge: Cambridge University Press, 1999.

KEHDI, Valdir. Formação de palavras em português. São Paulo: Ática, 1992.

KENSTOWICZ, Michael. Phonology in Generative Grammar. Oxford: Blackwell, 1994.

LEE, Seung-Hwa. Fonologia lexical do português. 1995. Tese (Doutorado) - IEL, Campinas.

MARANTZ, Alec. Re reduplication. Linguistic Inquiry 13(3), p. 435-482, 1982.

MONTEIRO, José. Morfologia portuguesa. Campinas: Pontes, 1991.

PRINCE, Alan; SMOLENSKY, Paul. Optimality Theory, 1993.

McCARTHY, John; PRINCE, Alan. Generalized Alignment. Yearbook of Morphology, 79-153, 1993.

McCARTHY, John; PRINCE, Alan. The emergence of unmarked. In: Proceedings of NELS 24: P. 333-79, Amherst: University of Massachussets, 1994.

McCARTHY, John; PRINCE, Alan. Prosodic morphology. In: GOLDSMITH, John. The handbook of phonological theory. Oxford: Blackwell, 1995.

NASH, D. Yidin ${ }^{y}$ stress: a metrical account. Cuny forum 7/8, p. 112-130, 1980.

PRINCE, Alan; SMOLENSKY, Paul. Optimality Theory. ms. Rutgers Univ., 1993.

RIO-TORTO. Mecanismos de produção lexical no português europeu. Alfa, 42 (no especial), p. 15-32, 1998.

SANDMANN, Antônio. Morfologia lexical. São Paulo: Contexto, 1991.

VIGÁRIO, Marina. Palavra prosódica e composição no português europeu. In: Actas do XV Encontro Nacional da Associação Portuguesa de Lingüística, Braga: APL, v.II, p. 583-602, 2000.

WETZELS, Leo. Mid-vowels alternations in the Brazilian Portuguese. Phonology, 12, 281-304, 1995.

WETZELS, W. Leo. Mid Vowel Neutralization in Brazilian Portuguese. Cadernos de Estudos Lingüisticos 23, Unicamp, Campinas, p. 18-55, 1992.

WILBUR, Ronnie. The phonology of reduplication. 1974. Tese (Doutorado) - University of Illinois. Distribuída por Indiana University Linguistic Club: Bloomington. 


\section{ANEXO}

\section{Truncamentos}

(Dados: dialeto paulista, gaúcho, exceto menção em contrário)

$\begin{array}{ll}\text { cerveja } & \text { cérva } \\ \text { despacilina } & \text { déspa } \\ \text { flagrante } & \text { flágra } \\ \text { jabuticaba } & \text { jabú } \\ \text { labrador } & \text { lábra } \\ \text { neurose } & \text { nêura } \\ \text { palhaço } & \text { pálha } \\ \text { pervertida } & \text { pérva } \\ \text { piscina } & \text { písça } \\ \text { professor } & \text { prófi } \\ \text { profissional } & \text { profí } \\ & \text { prófi (dialeto mineiro, segundo um parecerista) } \\ \text { retardado } & \text { rêta } \\ \text { truncamento } & \text { trunca } \\ \text { bijuteria } & \text { bijú } \\ \text { refrigerante } & \text { refrí } \\ & \text { réfri (paraense) } \\ \text { refrigerador } & \text { réfri } \\ \text { exposição } & \text { éxpo/expô } \\ \text { kilimanjaro } & \text { kíli/kilí } \\ \text { comunista } & \text { comuna } \\ \text { delegado } & \text { deléga } \\ \text { português } & \text { portúga } \\ \text { responsabilidade } & \text { respónsa } \\ \text { salafrário } & \text { saláfra } \\ \text { traficante } & \text { trafíca } \\ \text { Reduplicação } & \end{array}$

\section{Reduplicação}

Dados: Dicionário Aurélio (DA) (FERREIRA, 2000), COUTO (1999, 2000) e informantes. 
agarra-agarra

bate-bate*

beija-beija

bule-bule*

bole-bole

cai-cai

canta-canta

coça-coça

cheira-cheira*

corre-corre*

corrói-corrói

empurra-empurra* contatos excessivamente voluptuosos; movimento constante de dois objetos que se chocam. No parque de diversões, carrinhos elétricos próprios para se trombarem;

ação das pessoas se beijando umas às outras;

jogo de roda, iniciado por uma criança, que se volta para o vizinho da direita e, repetindo algum gesto com as mãos (como agitálas, p. ex.), pergunta-lhe: “-Quer comprar um bule-bule?" - ao que a outra indaga: "-Que bule-bule?" -, tendo como resposta: "- Aquele que bole, bole." Põe-se, então, a segunda a imitar o gesto da primeira (que continua a fazê-lo), dirigindo-se à terceira da roda para com ela travar o mesmo diálogo, e assim por diante, até que todas fiquem gesticulando igualmente, cabendo à primeira recomeçar a brincadeira com um novo movimento (DA);

requebro, rebolado, remelexo (DA);

em um esporte coletivo, diz-se quando um jogador e seqüencialmente outros caem ao chão, fingindo-se lesionados, a fim de se anular ou adiar o prosseguimento da partida;

ato repetitivo de cantar;

ato de coçar incessantemente;

adulador, bajulador. Por extensão aquele que cheira os pés do superior, em reverência;

correria, azáfama;

brinquedo canino próprio para ser mordido (sobretudo por filhotes);

acotovelamento, confusão; 
esconde-esconde* jogo infantil em que uma criança deve sair à procura das demais, que se esconderam (DA). A brincadeira tem várias rodadas, a fim de eliminar os que são encontrados primeiramente;

fecha-fecha*

fechamento generalizado de casas comerciais, bancos, etc. quando ocorrem perturbações da ordem pública, desordens, barulhos, etc. (DA);

foge-foge*

gira-gira

lambe-lambe*

leva-leva*

lufa-lufa*

luze-luze*

mata-mata*

marche-marche* mela-mela*

mexe-mexe*

mija-mija* correria ou fuga provocada por pânico (DA); no parque de diversões, brinquedo que gira dezenas de vezes;

lamber repetitivamente. O fotógrafo ambulante também recebe esse nome; grande agitação, rebuliço intenso (DA); grande afã, grande pressa ou agitação (DA); pirilampo (talvez por luzir repetitivamente); nos esportes, diz-se do sistema de eliminação no qual há um número de partidas e o vencedor é aquele que consegue o maior número inatingível de vitórias (ou pontos ou alguma outra vantagem pré-estabelecida). Por exemplo, numa série de cinco jogos, vence quem primeiro atingir três vitórias; marchar apressadamente;

brincadeira do carnaval de rua de Recife em que os foliões atiram água, talco e goma uns nos outros (DA);

jogo em que os parceiros, utilizando pequenas peças representativas das letras do alfabeto, tentam formar palavras sobre um tabuleiro, contando-se os pontos conforme as letras empregadas e a posição da palavra no tabuleiro (DA);

molusco bivalve, da família dos cardí́deos (Trachycardium muricatum), comestível, da costa atlântica, de concha quase circular 
pega-pega*

põe-põe

pinga-pinga*

pisca-pisca*

pula-pula*

puxa-puxa*

quebra-quebra*

range-range*

raspa-raspa*

rela-rela

rema-rema*

roça-roça

rói-rói* e com sulcos longitudinais que partem do ápice, irradiando-se para a periferia em forma de leque. O nome provém de lançarem jatos de água ao locomoverem-se (DA); conflito, briga (DA);

ato de pôr (alguma coisa em algum lugar ou em alguém) repetitivamente;

aquilo que pinga ou rende aos poucos sucessivamente (DA);

ato ou movimento de piscar seguidamente (DA);

um certo tipo de pássaro (DA). Uma brincadeira que consiste em pular repetitivamente sobre um colchão ou coisa parecida;

diz-se do doce ou da bala de consistência elástica e grudenta (DA);

arruaça, depredação;

rangido contínuo, constante (DA);

raspas de gelo servidas no copo com xarope de fruta; gelada (DA). Loteria instantânea;

forró. Supostamente as pessoas ficam se "relando" (ralando em alguns dialeto); brinquedo que consiste num veículo que tem como assento uma tábua e cuja tração é feita por uma alavanca que a criança impele com movimentos semelhantes aos dos remadores ou espécie de balanço, comuníssimo em parques infantis: uma prancha alongada e suspensa a uma armação por tubos de ferro, na qual os meninos se embalam, fazendo movimentos que lembram remadas (DA);

ver rela-rela;

brinquedo (típico do Nordeste do Brasil) consistindo de uma tábua volteada no ar por meio de uma corda com o fim de 
rola-rola*

ruge-ruge*

serra-serra*

tange-tange*

treme-treme*

troca-troca*

vira-vira* produzir um zunido (DA). Ato de roer constantemente;

peça cilíndrica de madeira sobre a qual alguém desliza, numa tábua, equilibrandose e fazendo acrobacias (DA);

rumor produzido por qualquer coisa que range ou roça; rugido. Confusão (DA);

ato de serrar constantemente;

barulho contínuo provocado por instrumentos musicais desordenados;

tremor contínuo (DA);

Negociação que envolve troca de objetos usados por novos, de atletas, entre clubes, etc (DA). Ato sexual homossexual masculino; ato de virar constantemente. 